\title{
Correspondence
}

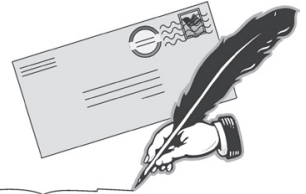

\section{Optimizing bupivacaine dosing for Cesarean delivery - I}

To the Editor:

I enjoyed reading the study by Bryson et al. ${ }^{1}$ in which the investigators compared low-dose isobaric spinal bupivacaine to a standard hyperbaric dose for Cesarean delivery. Their purpose was to identify if the lower dose, when combined with spinal fentanyl and morphine, could preserve efficacy while reducing the incidence of hypotension. Bryson et al. found that using a 4.5-mg dose of "isobaric" bupivacaine did not reduce the incidence of hypotension. In fact, both the 4.5-mg isobaric and the 12-mg hyperbaric groups had the same average cervical sensory level (C8) and, by inference, an equivalent sympathetic block. These results are somewhat surprising, since Van de Velde et $a l .{ }^{2}$ previously found that hyperbaric bupivacaine 6.5 $\mathrm{mg}$ was associated with a lower incidence of hypotension when compared with $9.5 \mathrm{mg}$ of hyperbaric bupivacaine. In that study, spinal blocks were performed in the sitting position (as in the study by Bryson et al.) and were augmented by epidural saline, if necessary, as part of a continuous spinal-epidural (CSE) technique.

The study by Bryson et al. shows that reducing the dose of bupivacaine in water will not ameliorate the hypotension associated with spinal anesthesia. A lower bupivacaine dose might lessen the incidence of respiratory compromise, since motor power is better preserved. One possible explanation is that $0.5 \%$ bupivacaine in water is actually slightly hypobaric, and the drug is rendered further hypobaric when mixed with fentanyl. ${ }^{3}$ This would account for the cervical levels of anesthesia achieved. In a study examining the effects of posture and baricity on spinal anesthesia, Hallworth et al. added $1.6 \mathrm{~mL}$ normal saline and $0.4 \mathrm{~mL}$ D5W to $8 \mathrm{~mL}$ of $0.5 \%$ bupivacaine to make an isobaric solution as measured by a density meter. ${ }^{4}$ A more easily obtained local anesthetic solution isobaric to CSF in pregnancy is $1 \%$ tetracaine in water. ${ }^{5,6} \mathrm{It}$ is prepared by adding $2 \mathrm{~mL}$ sterile water to a $20 \mathrm{mg}$ ampoule of lyophilized tetracaine.

Continuous spinal-epidural may be preferred to spinal anesthesia for Cesarean delivery, when preserving hemodynamic stability or avoiding airway compromise are particularly important, for example, in pre-eclamp- tic patients. ${ }^{7}$ The best features of each technique may be preserved. An isobaric spinal solution allows unhurried placement of the epidural catheter through the CSE needle in the sitting position. A cocktail of low-dose isobaric spinal tetracaine, augmented by intrathecal fentanyl, morphine, and epidural saline or local anesthetic, as necessary, may provide the most effective and balanced approach to these problems.

Peter Tinits MD FRCPC

Stratford General Hospital, Stratford, Canada

E-mail: ptinits144@rogers.com

Accepted for publication October 24, 2007.

\section{References}

1 Bryson GL, MacNeil R, Jeyaraj LM, Rosaeg OP. Small dose spinal bupivacaine for cesarean delivery does not reduce hypotension but accelerates motor recovery. Can J Anesth 2007; 54: 531-7.

2 Van de Velde M, Van Schoubroeck D, Jani J, Teunkens A, Missant C, Deprest J. Combined spinal-epidural anesthesia for cesarean delivery: dose-dependent effects of hyperbaric bupivacaine on maternal hemodynamics. Anesth Analg 2006; 103: 187-90.

3 Richardson $M G$, Wissler $R N$. Densities of dextrose-free intrathecal local anesthetics, opiods, and combination measured at $37^{\circ} \mathrm{C}$. Anesth Analg 1997; 84: 95-9.

4 Hallworth SP, Fernando R, Columb MO, Stocks GM. The effect of posture and baricity on the spread of intrathecal bupivacaine for elective cesarean delivery. Anesth Analg 2005; 100: 1159-65.

5 Greene NM. Distribution of local anesthetic solutions within the subarachnoid space. Anesth Analg 1985; 64: 715-30.

6 Lui AC, Polis TZ, Cicutti NJ. Densities of cerebrospinal fluid and spinal anaesthetic solutions in surgical patients at body temperature. Can J Anaesth 1998; 45: 297-303.

7 Guasch E, Dominguez A, Alsina E, Gilsanz F. Combined spinal-epidural anesthesia with very lowdose hyperbaric levobupivacaine for cesarean section in a pre-eclamptic patient. Int J Obstet Anesth 2007; 16: 91-3. 